\title{
A INDEPENDÊNCIA DAS AGÊNCIAS REGULADORAS E O INVESTIMENTO PRIVADO NO SETOR DE ENERGIA DE PAÍSES EM DESENVOLVIMENTO
}

\author{
Gisele Ferreira Tiryaki *
}

\begin{abstract}
Resumo
Investimentos no setor de energia têm prazo de maturação prolongado e envolvem um volume de significativo de custos irreversíveis. Práticas regulatórias transparentes, adotadas por entidades independentes e sujeitas ao escrutínio público, são frequentemente apontadas como essenciais para o estímulo ao engajamento de investidores privados em projetos de infraestrutura de energia. Utilizando informações levantadas sobre agências reguladoras do setor de energia de 87 países em desenvolvimento, elaborou-se um banco de dados com o nível de independência formal de cada uma dessas entidades. A análise econométrica desenvolvida utilizando esses dados indica que a autonomia das agências reguladoras é relevante para estimular o investimento privado no setor de energia, assim como o nível de renda e a estabilidade macroeconômica de um país.
\end{abstract}

Palavras-chave: Investimento Privado; Infraestrutura; Instituições Legais.

\begin{abstract}
Investment in the energy sector involves a significant volume of sunk costs on long-lived assets. Transparent regulatory practices adopted by independent regulatory agencies and subjected to the monitoring of the public are regarded as essential to foster private participation in energy projects. A database was created using information on the constitution and operating procedures of regulatory agencies in 87 developing countries to assess their level of formal independence. The econometric analysis based on this database indicates that the independence of regulatory agencies is relevant to promote private investment in the energy sector. The analysis also shows that income level and macroeconomic stability are key factors to encourage private participation in infrastructure projects in the energy sector of developing countries.
\end{abstract}

Keywords: Investment; Infrastructure; Legal Institutions.

JEL classification: Q4, L33, G38

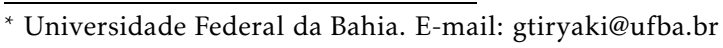




\section{Introdução}

O nível e a qualidade dos serviços de infraestrutura são determinantes para a produção e comercialização de bens e serviços, afetando a produtividade, custos e competitividade de uma economia e sendo, portanto, essenciais para a promoção do crescimento econômico (ver, dentre outros, Reinikka \& Svensson 1999, Calderon \& Serven 2003, Guasch 2004). Desde o início dos anos 90 , vem se observando uma participação ativa do setor privado na provisão de infraestrutura de países em desenvolvimento, fruto da busca por uma melhor eficiência operacional e da necessidade de captação de recursos em um contexto de restrições orçamentárias do setor público.

De acordo com dados do Banco Mundial (2011a), um volume de investimentos totalizando US\$ 1,788 bilhões já foi direcionado para projetos de infraestrutura com a participação do setor privado em 139 países em desenvolvimento entre 1990 e 2009 , sendo que um terço deste valor envolveu projetos no setor de energia. ${ }^{1}$ O Brasil liderou em termos de fluxo de investimentos canalizados para projetos de energia, sendo responsável por $21,4 \%$ do total direcionado para o setor no referido período.

A tecnologia utilizada em projetos no setor de energia, particularmente nos segmentos de transmissão e distribuição de eletricidade e de transporte dutoviário de gás natural, envolve um elevado volume de custos irreversíveis e investimento em ativos com baixo valor em termos de usos alternativos. Investidores privados, negociando com entidades governamentais têm maior poder de barganha ex ante, face às restrições orçamentárias do governo. No entanto, tão logo o projeto entre em fase operacional, o governo pode tentar impor mudanças no contrato inicial, levando em consideração que o investidor continuará operando desde que as receitas operacionais excedam os custos operacionais. Ou seja, na ausência de elementos que garantam a implementação futura de contratos preestabelecidos, o governo pode impor restrições nos preços, requerer investimentos adicionais e adotar outras medidas que podem representar, em última instância, o comprometimento dos ativos e da rentabilidade inicialmente pactuada (ver Henisz 2002, Banerjee et al. 2006).

Além disso, é possível observar um comportamento oportunístico por parte do investidor privado. A Teoria da Captura e a Teoria Econômica da Regulação, que têm por foco a formação de grupos de interesse e a captura de agentes reguladores, argumentam que as empresas possuem grande capacidade de organização e efetividade na busca de rendas extras ou rent seeking. Por consequência, de acordo com essas teorias, é possível observar as agências reguladoras cedendo ao lobby de grupos que representam os interesses de empresas ao invés de defender de forma mais efetiva os interesses dos consumidores (ver, por exemplo, Olson 1965, Stigler 1971, Peltzman 1976, dentre outros). Desta forma, a Teoria da Captura e a Teoria Econômica da Regulação avançam na análise da regulação em relação à tradicional Teoria do Interesse Público, que defendia o surgimento das agências reguladoras como fruto do interesse do governo em promover maior eficiência em mercados caracterizados por monopólios naturais, não levando em consideração, portanto, como as instituições políticas e econômicas impactavam sobre o comportamento de agentes reguladores (Dixit 1996, Viscusi et al. 2005).

\footnotetext{
${ }^{1} \mathrm{O}$ setor de energia engloba geração, transmissão e distribuição de eletricidade e transporte dutoviário de gás natural.
} 
É essencial, portanto, a adoção de práticas regulatórias transparentes e, frequentemente, defende-se também a importância da independência das agências reguladoras, como forma do governo sinalizar seu comprometimento com os arranjos regulatórios estabelecidos, mitigando também a incerteza política (ver Levy \& Spiller 1996, Gilardi 2006). A independência formal per se não garante, contudo, uma maior estabilidade e confiança no arcabouço regulatório. A existência de uma legislação de constituição de agência reguladora que, a princípio, contenha elementos favoráveis à independência não é suficiente para asseverar autonomia de fato. Além disso, não garante que agentes reguladores atuarão sem influência dominante de determinados grupos de interesse. Presume-se, assim, que aspectos de governança, como o respeito aos preceitos legais, controle da corrupção, qualidade da regulação e isenção do judiciário sejam também essenciais.

Nos setores de infraestrutura, o estabelecimento de agências reguladoras independentes tem sido mais prevalente em telecomunicações e energia. Alguns trabalhos empíricos no setor de telecomunicações indicam que a existência de agências reguladoras autônomas está associada a um desempenho operacional mais eficiente e a uma melhor provisão de infraestrutura (ver Gutierrez 2003, Gual \& Trillas 2004). O presente trabalho, por sua vez, dedicou-se a investigar como o nível de independência formal de entidades reguladoras tem afetado a participação do setor privado em projetos de energia em países em desenvolvimento. Para isso, fez-se um levantamento de informações referentes à constituição e operacionalização de entidades reguladoras do setor de energia de 87 países em desenvolvimento e conduziu-se uma análise de dados em cross-section, controlando para a importância de outros fatores determinantes do fluxo de investimento, como aspectos de governança, do ambiente de negócios, nível de renda, nível de industrialização e intensidade energética.

Os resultados obtidos demonstram que, para se estimular o interesse do setor privado em participar de projetos no setor de energia, a independência da entidade reguladora é relevante, além de ser mais interessante para o setor privado investir em países com renda mais elevada e com maior estabilidade macroeconômica. A autonomia das entidades reguladoras aparenta ser mais relevante do que aspectos de governança, ${ }^{2}$ muito embora seja importante salientar que a existência de legislação favorável à independência não garante que a autonomia de fato prevaleça.

A conexão entre qualidade institucional e desempenho de setores de infraestrutura também já foi analisada, mas com metodologia ou foco diferenciado do apresentado aqui. Pargal (2003), por exemplo, salientou a importância da independência e credibilidade do regulador para o clima de investimento em infraestrutura, mas sua análise incluiu dados de apenas nove países na América Latina. O presente estudo inova ao estimar o nível de independência para uma amostra mais representativa de países e mostra que esses resultados são mantidos quando analisamos o setor de energia.

Cubbin \& Stern (2005), por sua vez, estabeleceram a conexão entre aspectos institucionais e a eficiência na provisão de eletricidade em países em desenvolvimento, mas não estabeleceram a conexão com o fluxo de investimento

\footnotetext{
${ }^{2}$ Assim como em Kaufmann et al. (2010), governança é relacionada às tradições e instituições que estabelecem como a autoridade é exercida em um determinado país. Aspectos de governança incluem o nível de estabilidade política, a capacidade do governo em elaborar políticas efetivas e o respeito dos cidadãos e do governo pelas instituições que regem as interações econômicas e sociais.
} 
envolvendo o setor privado. Bergara et al. (1997) e Henisz (2002) limitaramse a analisar a importância de instituições políticas sólidas para a provisão de capacidade de geração de energia, não levando em consideração os demais indicadores de governança e variáveis representando ambiente para negócios. Jensen \& Blanc-Brude (2006) apontaram para o aumento na probabilidade de envolvimento do setor privado no setor de água e saneamento na presença de indicadores de governança mais robustos, enquanto Tiryaki $(2008 b, a)$ encontra semelhante resultados, apontando para importância de aspectos institucionais para o investimento privado em infraestrutura e no setor de energia, respectivamente. Nenhum desses trabalhos buscou estimar e incorporar nas suas análises a relevância da independência das agências reguladoras para o investimento privado em infraestrutura.

Já para Banerjee et al. (2006), a proteção aos direitos de propriedade e qualidade da burocracia são os principais determinantes de investimentos em infraestrutura com participação do setor privado. Esses autores também apontam para o fato de que países com corrupção elevada vêm atraindo um maior fluxo de investimento em infraestrutura (resultado não consubstanciado com a evidência empírica apresentada a seguir).

O presente artigo está organizado em quatro seções, incluindo esta introdução. A seção 2 descreve as variáveis utilizadas, enquanto a seção 3 discute a metodologia empregada, os resultados obtidos e a robustez da análise econométrica. A seção 4 apresenta as considerações finais.

\section{Dados Estatísticos}

A escolha dos países incluídos na amostra foi feita com base na disponibilidade de informações sobre o investimento privado no setor de energia e sobre a independência das agências reguladoras. De um total de 107 países em desenvolvimento onde há evidência de envolvimento do setor privado em projetos de energia, foram encontrados dados que permitiram construir o indicador de independência da entidade reguladora para 87 países, sendo que, para sete desses países, o envolvimento do setor privado se restringiu ao gerenciamento de projetos sem comprometimento de investimento de recursos ${ }^{3}$. A amostra contém, portanto, cerca de $80 \%$ dos países com potencial para serem incluídos no estudo, sendo que os países incluídos apresentam graus variados de participação do setor privado, bem como características distintas no que se refere às demais variáveis incorporadas ao modelo econométrico (logo, o potencial de viés de seleção foi minimizado).

Os valores dos investimentos direcionados ao setor de energia foram obtidos no PPI Database Banco Mundial (2011a). Estes valores representam investimentos em projetos de infraestrutura do setor de energia com a participação do setor privado. ${ }^{4}$ Expressos originalmente em termos nominais, os investimentos anuais de cada país foram convertidos para valores reais utilizando-se o ano 2009 como base, agregados durante o período entre 1990 e 2009 e divididos pela população média do país no mesmo período.

\footnotetext{
${ }^{3}$ A lista de países presentes na amostra, bem como a fonte das informações sobre independência das agências reguladoras encontram-se na Tabela A.1 do Apêndice

${ }^{4}$ Os projetos podem ter sido implementados exclusivamente por agentes privados ou sob forma de joint venture com empresas públicas, sendo que, no caso de parcerias público-privadas, não é possível obter do banco de dados somente o valor do investimento privado.
} 
A estratégia de agregação do investimento no período em questão teve por objetivo resolver distorções que poderiam emergir em razão da metodologia adotada pelo PPI Database no registro dos dados estatísticos. Para os projetos de energia que envolvem construção de novas unidades geradoras de energia (greenfield), por exemplo, o valor de investimento registrado reflete o volume total de recursos a ser investido na construção, cujo financiamento (com recursos internos dos participantes ou de terceiros) já foi comprovadamente acertado; para projetos que envolvem investimentos em unidades existentes (brownfield), o valor registrado do investimento pode refletir, a depender dos termos do contrato de concessão estabelecido, o investimento anual em infraestrutura realizado pela empresa que gere o projeto ou o comprometimento de investimento durante a duração do contrato. ${ }^{5}$ Desta forma, a variável que representa o investimento agregado deve ser interpretada como um indicativo da disposição de agentes privados em investir no setor de energia de determinado país.

Essa particularidade no registro dos dados estatísticos dificulta a realização de análise em painel, já que os valores anuais de investimento em cada país refletem, ao mesmo tempo, investimento anual e comprometimento de investimento por longos períodos de tempo (o período de uma concessão varia significativamente entre os países, sendo, em média, em torno de 35 anos). Além disso, a análise em painel também é inviabilizada pelo fato de que o indicador de independência da entidade reguladora, conforme descrito mais detalhadamente a seguir, não possui dimensão temporal.

Para permitir a comparação da extensão da participação privada em infraestrutura entre os diversos países, os testes conduzidos aqui utilizaram o logaritmo do investimento em infraestrutura em energia por habitante (PPIEN) como variável dependente. Alternativamente, poderia se calcular os valores investidos em termos do produto interno bruto (PIB), mas os resultados obtidos não seriam representativos, visto que, como indicado anteriormente, os valores obtidos no PPI Database podem representar o total a ser investido durante o período de uma concessão, ao invés de gastos anuais.

$\mathrm{O}$ uso do volume de investimentos em termos globais distorceria os resultados dos testes econométricos discutidos a seguir. O Brasil, por exemplo, ocupa a primeira colocação no ranking dos países com maior volume de recursos destinados a projetos de eletricidade e gás natural, mas é o nono colocado quando se considera o volume de investimento per capita. A Índia, por sua vez, ocupa a segunda colocação em termos de investimento global e a quinquagésima posição em investimento per capita. A Tabela 1 apresenta o ranking dos países de acordo com o investimento global e investimento per capita em projetos de energia com a participação do setor privado.

\subsection{Independência Formal das Agências Reguladoras}

O processo de reforma regulatória que vem sendo implementado nos setores de infraestrutura de vários países desenvolvidos e em desenvolvimento envolve inúmeras dimensões, tais como a desverticalização, o nível de abertura do mercado para novos agentes, a assimetria das políticas de desregulamentação e o nível de independência das entidades reguladoras.

\footnotetext{
${ }^{5}$ Para a metodologia utilizada pelo PPI Database, ver Banco Mundial (2011a).
} 


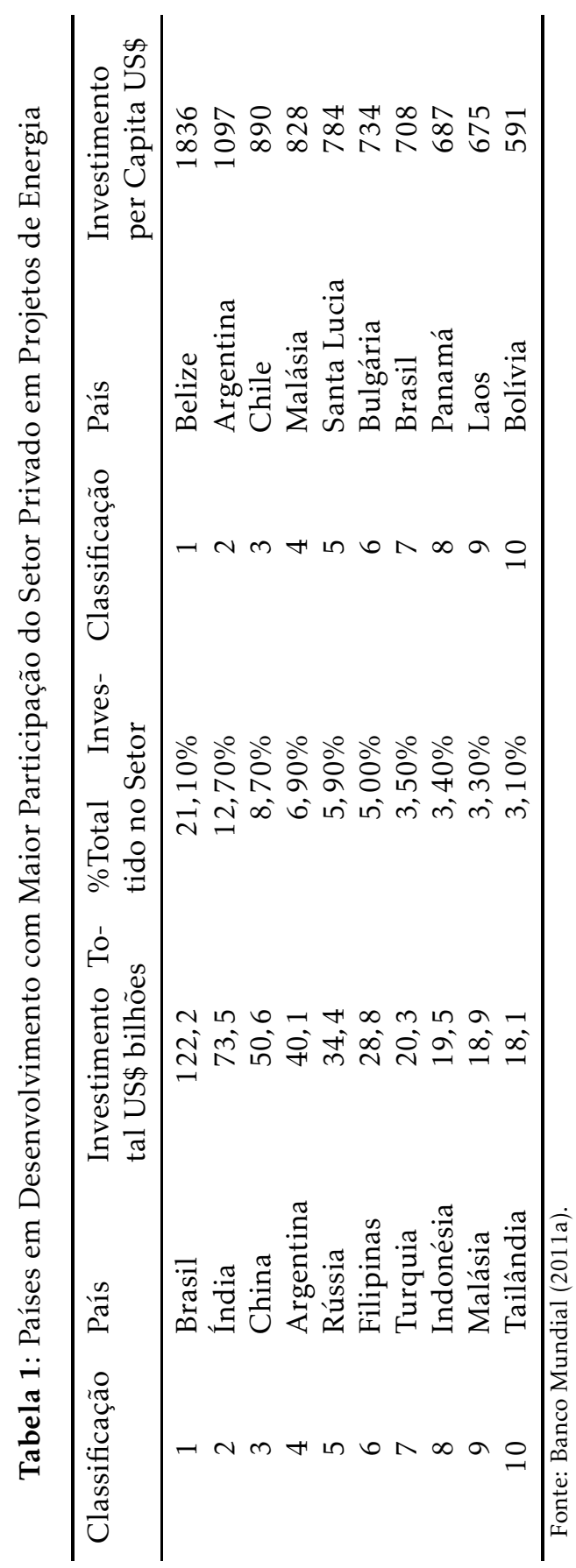


Conceder uma maior autonomia às agências reguladoras é uma estratégia utilizada para conferir maior credibilidade aos demais aspectos regulatórios da reforma, o que é essencial para os setores de infraestrutura em particular, onde os efeitos negativos de mudanças no arcabouço regulatório são mais significativos (face ao elevado volume de investimentos irreversíveis). Alternativamente, criar mecanismos que viabilizem a independência das agências pode ser uma forma de se lidar com a incerteza política, ou seja, com a possibilidade de que regras estabelecidas sejam revertidas com mudanças políticas. Independentemente da motivação, espera-se que a existência de entidades autônomas confira a credibilidade necessária à atração e retenção do investimento privado, particularmente nos setores de infraestrutura.

Mensurar o nível de independência de uma agência reguladora não é uma tarefa sem percalços, visto que a existência de independência formal, per se, não necessariamente implica em independência de facto. Mais ainda, é provável que a independência informal tenha mais importância do que aquela estabelecida nos atos de constituição e funcionamento das agências. Não obstante, estabelecer critérios comparativos de independência informal envolve obstáculos ainda mais significativos, em face da necessidade de se utilizar critérios subjetivos.

O presente trabalho utilizou a metodologia adotada por Gilardi (2006) para calcular o indicador de independência das agências reguladoras do setor de energia dos países em desenvolvimento incluídos na amostra. Salientase que o indicador de independência, conforme descrição detalhada a seguir, foca quase que exclusivamente em independência dos agentes reguladores em relação aos políticos eleitos (executivo e legislativo). Portanto, inclui apenas de forma marginal aspectos relacionados à captura dos agentes reguladores pela indústria, ${ }^{6}$ uma possibilidade relevante e que tem implicações significativas em termos de eficiência econômica e alocativa. A inclusão de variáveis de governança institucional nos testes econométricos, mesmo não resolvendo a questão, mitiga essa deficiência, pois captura a facilidade com que os agentes econômicos conseguiriam burlar a legislação em seu favor.

Diferentemente de Wallsten (2002) e Estache \& Goicoechea (2005), que se utilizam apenas de uma variável dummy indicando a existência ou ausência de uma agência reguladora, o índice geral de independência (INDEP) utilizado no presente trabalho incorpora as cinco dimensões da constituição e operacionalização das entidades reguladoras sugeridas por Gilardi (2006): a autonomia do diretor geral, autonomia dos demais dirigentes da entidade, o relacionamento com o executivo e legislativo, a autonomia financeira e organizacional e a competência regulatória. Para cada uma dessas dimensões, vários aspectos foram levados em consideração e pontuados de forma diferenciada, conforme detalhado na Tabela 2.

A pontuação atribuída para cada dimensão refletiu a média aritmética dos valores aferidos a cada aspecto, sendo que esses valores variaram entre zero e um. Valores maiores estão associados a características na organização e operacionalização das entidades reguladoras que conferem maior independência, com exceção da dimensão de competência, que se refere apenas à instância que detém a capacidade de estabelecer a regulação do setor. ${ }^{7} \mathrm{O}$ índice geral

\footnotetext{
${ }^{6}$ Como apresentado a seguir na Tabela 2, procura-se contabilizar a possibilidade de captura do agência ao verificar se a independência é um requisito formal para indicação dos membros da diretoria geral das entidades reguladoras.

${ }^{7}$ Em tese, é possível ter uma agência reguladora relativamente independente, mas com escopo
} 
de independência do agente regulador de cada país foi obtido calculando-se a média simples das cinco dimensões, já que foi atribuído o mesmo peso para cada dimensão.

A escolha da importância de cada aspecto foi uma decisão ad hoc do referido autor, sendo, portanto, um dos principais problemas da metodologia dos trabalhos que se dedicam ao cálculo do nível de independência das agências reguladoras (ver Oliveira et al. 2005). Acredita-se, contudo, que para efeito de comparação entre diversas entidades reguladoras, esse índice capta de forma satisfatória o nível de independência formal.

A Tabela A.1 do Apêndice contém a fonte das informações sobre independência das agências reguladoras, com indicações de legislações ou atos regulatórios relevantes e ano de implementação. É importante salientar que a versão desses documentos utilizada no cálculo do indicador de independência foi a mais atualizada que estava disponível; ou seja, procurou-se utilizar aqueles documentos que já tinham incorporado as modificações que por ventura foram acontecendo ao longo do tempo. Os valores estimados das cinco dimensões utilizadas no cálculo do indicador de independência das entidades reguladoras de cada país da amostra estão apresentados na Tabela A.2 do Apêndice.

De forma complementar a Gilardi (2006), cuja análise teve por foco estimar o grau de independência de entidades reguladores de diversos setores em 17 países europeus, o presente trabalho fez o levantamento de informações de documentos legais de constituição e operacionalização das entidades reguladoras do setor de energia de 88 países em desenvolvimento. Quando os segmentos de gás natural e de eletricidade possuíam agências reguladoras distintas, optou-se por calcular o indicador da agência do segmento de eletricidade. Esta escolha foi feita em função de que, em seis dos sete casos em que isso ocorreu, o setor de eletricidade atraiu um volume de investimento muito mais significativo do que o setor de gás natural (a exceção foi a Argentina, onde os investimentos encontram-se quase que igualmente distribuídos entre os dois segmentos).

Dadas às dificuldades de se incorporar uma variação temporal à variável INDEP $^{8}$ e aos problemas apontados acima com a metodologia do PPI Database em tentativas de se fazer análise temporal do investimento privado, optou-se pela análise em cross section, descrita em detalhes na seção sobre metodologia. Essa escolha envolve custos, já que a amostra contém países em diferentes estágios de privatização e com diferentes graus de institucionalização das entidades reguladoras.

Para minimizar esses vieses, as seguintes estratégias foram adotadas. Primeiramente, foram utilizados valores agregados de investimento em projetos com envolvimento do setor privado em termos per capita, pois se espera que países em estágios mais avançados de privatização apresentem valores mais elevados de investimento por habitante. Em relação aos diferentes graus de institucionalização das entidades reguladoras, foram incluídas outras va-

de atuação limitado, com a política regulatória sendo decidida pelo executivo e legislativo. Para o cálculo do índice geral de independência, assume-se que maior competência regulatória contribui para a independência da entidade reguladora.

${ }^{8} \mathrm{O}$ acompanhamento das variações legais nos documentos de constituição das entidades reguladoras durante o período em análise não foi viável em função da indisponibilidade de documentos. Optou-se, assim, por analisar a versão do documento de constituição que melhor incorporasse as inovações que ocorreram no período em questão. 


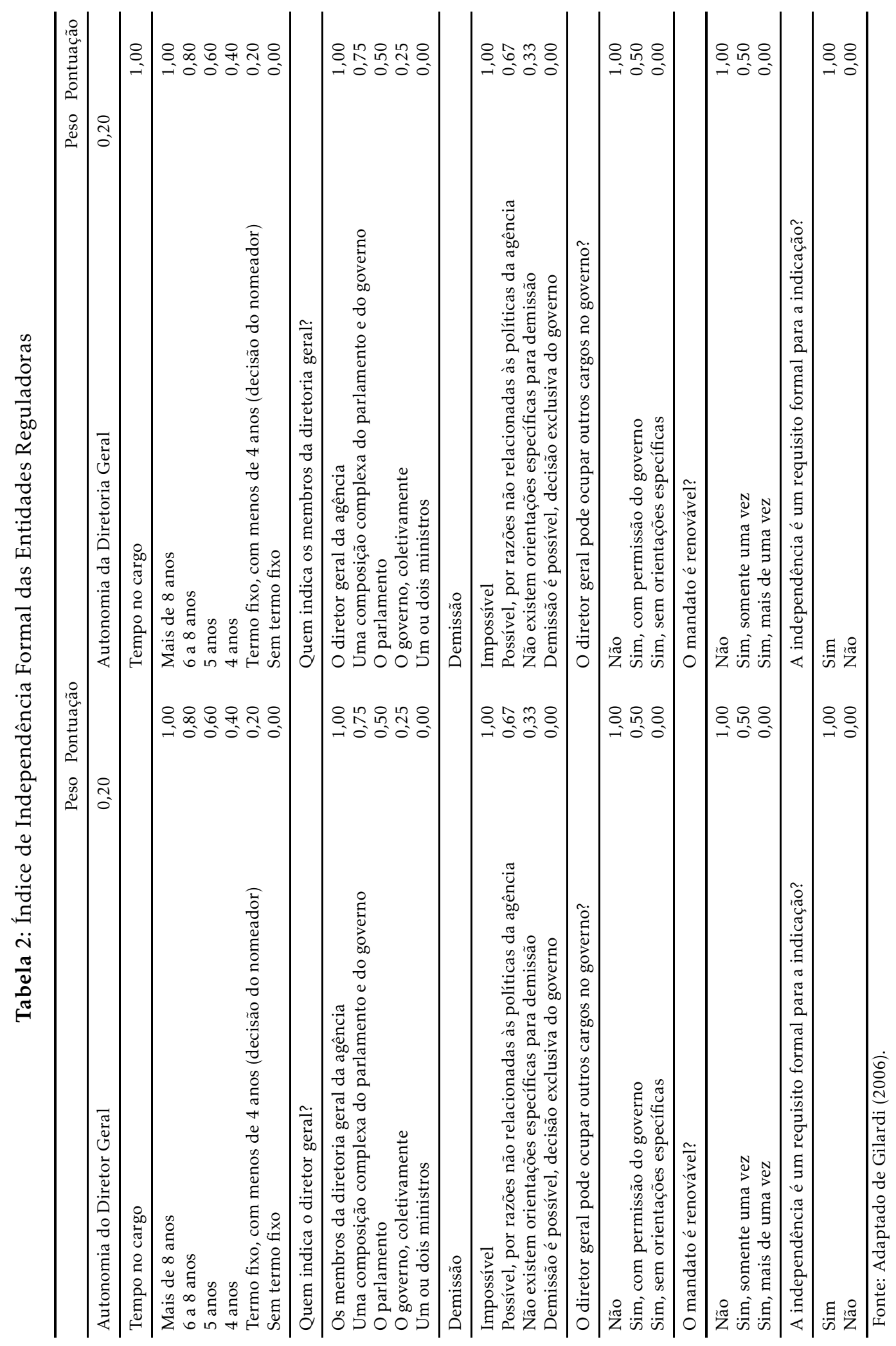




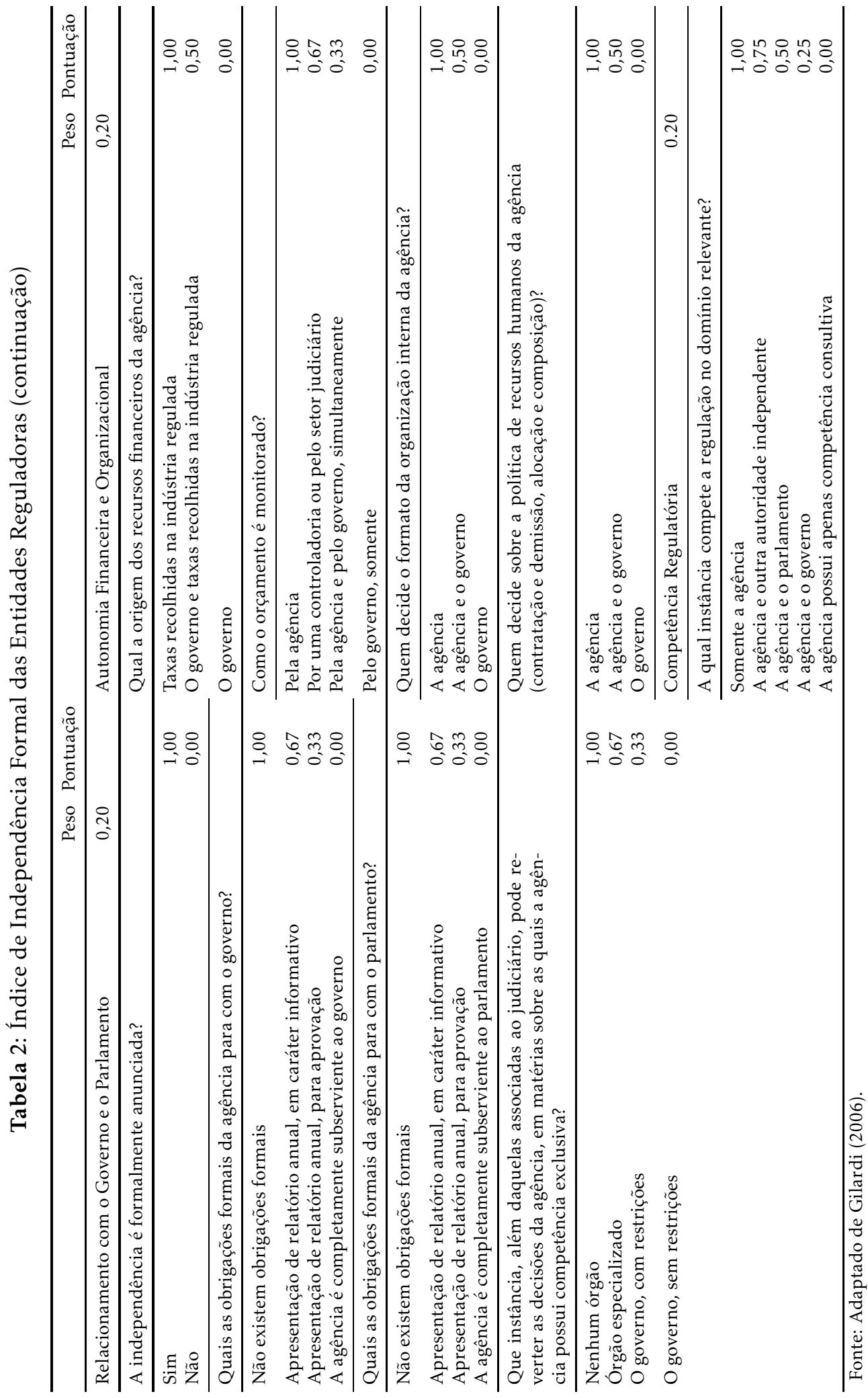


riáveis independentes relevantes para o processo de privatização, particularmente variáveis de governança institucional, que têm o potencial de capturar essas diferenças no grau de institucionalização. Acredita-se, contudo, que esses vieses não comprometam significativamente os resultados, tendo em vista que, em quase dois terços da amostra, o envolvimento do setor privado iniciouse ou tornou-se mais relevante quase que simultaneamente com o estabelecimento formal da entidade reguladora.

\subsection{Variáveis de Controle}

Além das variáveis representando a independência das agências reguladoras, foram incluídas, nas análises de regressão, variáveis adicionais para controlar o impacto de outros fatores que determinam os investimentos em projetos no setor de energia com a participação do setor privado.

Existe consenso que a existência de um arcabouço regulatório robusto, a estabilidade política e macroeconômica e a credibilidade das políticas governamentais reduzem o risco de expropriação formal e informal e estimulam o investimento privado. Vários indicadores foram utilizados para indicar a qualidade institucional e o ambiente de negócios de um país: ${ }^{9}$

- Tradição Legal (LEIS): essa variável mede a tradição de cada país no que se refere a preceitos legais e de ordem; ou seja, mede o nível de confiança e respeito que os indivíduos têm para com o sistema legal. Vários aspectos são levados em consideração na construção deste indicador, tais como segurança de contratos estabelecidos (entre entes privados e com o governo), a proteção aos direitos de propriedade, a qualidade do policiamento, a independência e efetividade do sistema judiciário e a transparência e responsabilização do executivo. ${ }^{10} \mathrm{O}$ índice varia entre $-2,5$ e 2,5, com valores menores refletindo maior impunidade para com o descumprimento de obrigações legais;

- Qualidade da regulação (REGQUAL): esse indicador reflete a incidência de políticas e de legislação que limitam as forças de mercado, como, por exemplo, a existência de controles de preço e supervisão inadequada do sistema financeiro, e a imposição excessiva de regulação em áreas como comércio internacional e desenvolvimento de negócios. O índice varia entre $-2,5$ e 2,5, com valores menores refletindo pior qualidade da regulação;

- Controle da Corrupção (CCORRUP): esta variável é uma estimativa do nível em que agentes governamentais utilizam-se do seu poder político para ganho privado. O índice varia entre -2, 5 e 2,5, com valores menores representando um menor controle da corrupção;

- Estabilidade Política (ESTPOL): esta variável é uma combinação de vários indicadores que medem a percepção que existe entre agentes econômicos da probabilidade que um governo seja desestabilizado ou desti-

\footnotetext{
${ }^{9}$ Foi calculada a mediana para cada uma dessas variáveis no período em questão, desde que os dados estivessem disponíveis, exceto para a variável de estabilidade macroeconômica, detalhada a seguir.

${ }^{10}$ Esse último aspecto sobre a atuação do executivo refere-se ao termo accountability, ainda de difícil tradução para o português.
} 
tuído, possivelmente de maneira inconstitucional ou por formas violentas. O índice varia entre $-2,5$ e 2,5, com valores menores representando maior instabilidade política;

- Eficiência do Governo (EFICGOV): mede-se, aqui, as percepções sobre a qualidade na provisão de serviços públicos, qualidade da burocracia, credibilidade na execução de políticas delineadas, competência dos servidores públicos e nível de independência destes para com pressões políticas. O índice varia entre $-2,5$ e 2,5, com valores menores representando uma menor eficiência das políticas governamentais;

- Facilidade na implementação e operação de negócios: cinco variáveis foram selecionadas como indicadores da facilidade na realização de negócios: o custo de se iniciar um negócio em relação à renda per capita (CINIC); o custo com a obtenção de alvará de construção em relação à renda per capita (PERMIT); o custo com registro de propriedade em relação ao valor total da propriedade (CREGPROP); o índice do grau de proteção ao investidor, que varia de zero a dez, com valores maiores indicando maior proteção (PROTINV); e a taxa total de impostos em relação aos lucros (PESOIMP); e,

- Estabilidade macroeconômica (INFMED): calculou-se a inflação mediana de cada país entre 1990 e 2004. Investidores resistem em direcionar recursos para países de economia instável, principalmente quando o horizonte de investimento é prolongado. Particularmente em energia, existe um agravante adicional, pois governos de países com taxas de inflação elevadas frequentemente manipulam preços de insumos energéticos como forma de conter altas gerais de preços.

As primeiras cinco variáveis representam aspectos de governança (Banco Mundial 2011b). As últimas variáveis, por sua vez, indicam as condições de investimento em um país: os indicadores de facilidade na implementação e operação de negócios tiveram por fonte o Doing Business Database (Banco Mundial 2011c) e a INFMED foi obtida do World Economic Outlook Database (Fundo Monetário Internacional 2006).

Adicionou-se, ainda, à análise de regressão, a mediana do logaritmo da renda per capita de cada país - em dólares americanos com ano base 2009 - expressa em termos de paridade de poder de compra (RENDA), a mediana do percentual do valor adicionado da indústria em relação ao PIB (INDUSTRIA) e a mediana da razão entre a unidade de utilização de energia e o PIB (EFENERG), entre 1990 e 2009. ${ }^{11}$

Países com renda elevada tendem a atrair mais investimentos do setor privado, visto que a demanda em potencial por infraestrutura tende a ser mais elevada. Por exemplo, em países com renda mais elevada, a população tende a fazer maior uso de eletricidade e gás natural (ver, por exemplo, Bergara et al. 1997). Quanto mais representativo o setor industrial, por sua vez, maior o potencial para cogeração e maior a demanda por eletricidade. Por fim, investimentos tendem a fluir de forma mais representativa para países em que a

\footnotetext{
${ }^{11}$ EFENERG é obtido calculando-se o inverso do valor do PIB em paridade de poder de compra por $\mathrm{kg}$ de óleo equivalente. RENDA, INDUSTRIA e EFENERG foram obtidas em Banco Mundial (2011d).
} 
utilização de energia em relação ao PIB é reduzida, visto que há um maior potencial de crescimento da demanda por energia nesses países (maior retorno marginal no estoque de capital).

A Tabela 3 apresenta as estatísticas descritivas das variáveis utilizadas na análise econométrica, enquanto a Tabela 4 expõe a correlação em pares. É interessante notar que a independência das agências não é significativamente correlacionada com os indicadores de governança institucional, o que pode indicar que o indicador de independência formal pode não refletir independência real. Em vários países, o processo de estabelecimento da entidade reguladora se deu de forma exógena, por influência direta ou imposição por parte de instituições multilaterais, o que não garante que sua operacionalização necessariamente siga as regras estabelecidas.

$\mathrm{O}$ fato de que os indicadores de governança institucional apresentam, a priori, maior correlação com a PPIEN do que com o INDEP também aparenta indicar que onde há instituições robustas, a independência formal tem um papel secundário. Não obstante, conforme demonstrado nos resultados apresentados na seção a seguir, o indicador de independência formal é estatisticamente significativo e economicamente relevante para o engajamento do setor privado em projetos de energia.

Ainda na Tabela 4, observa-se que os indicadores de governança (LEIS, REGQUAL, CCORRUP, ESTPOL e EFICGOV) apresentam elevada correlação em pares, o que pode levar a problemas de multicolinearidade se incluídos simultaneamente nas análises de regressão. Tal padrão também é observado em dois dos indicadores de facilidade de negócios (CINIC e PERMIT). Uma estratégia para lidar com a possibilidade de multicolinearidade é a condução de análise fatorial, descrita na seção a seguir, que permite a estimativa de um índice representativo das dimensões latentes que resumem as variáveis observadas em questão.

Tabela 3: Estatísticas Descritivas das Variáveis de Controle

\begin{tabular}{lrrrrrr}
\hline & Média & Mediana & Máximo & Mínimo & $\sigma$ & No. Obs. \\
\hline INDEP & 0,509 & 0,544 & 0,864 & 0,000 & 0,247 & 87 \\
LEIS & $-0,384$ & $-0,461$ & 1,249 & $-1,736$ & 0,608 & 88 \\
REGQUAL & $-0,213$ & $-0,279$ & 1,483 & $-2,236$ & 0,619 & 88 \\
CCORRUP & $-0,397$ & $-0,473$ & 1,371 & $-1,626$ & 0,587 & 88 \\
ESTPOL & $-0,315$ & $-0,226$ & 0,976 & $-1,917$ & 0,738 & 88 \\
EFICGOV & $-0,285$ & $-0,364$ & 1,240 & $-1,531$ & 0,548 & 88 \\
CINIC & 76,22 & 28,44 & 1363,43 & 1,050 & 167,60 & 86 \\
CPERMIT & 1597,47 & 377,14 & 75933,62 & 6,85 & 8177,48 & 86 \\
CREGPROP & 6,539 & 5,070 & 23,480 & 0,260 & 5,220 & 86 \\
PROTINV & 4,919 & 5,000 & 8,700 & 1,700 & 1,284 & 86 \\
PESOIMP & 47,237 & 42,163 & 290,875 & 15,350 & 30,499 & 86 \\
INFMED & 1,981 & 2,019 & 4,832 & 0,226 & 0,836 & 87 \\
RENDA & 8,271 & 8,424 & 9,679 & 6,425 & 0,910 & 88 \\
INDUSTRIA & 29,475 & 28,574 & 66,618 & 9,871 & 9,911 & 88 \\
EFENERG & 5,061 & 4,688 & 11,882 & 0,298 & 2,616 & 66 \\
\hline
\end{tabular}

Nota: $\sigma$ representa o desvio padrão.

\section{Procedimentos Metodológicos e Resultados}

Existe uma série de variáveis com potencial para influenciar o grau de envolvimento do setor privado no setor de energia. Particularmente no que se refere 
Tabela 4: Correlação em Pares

\begin{tabular}{lrrrrrrrr}
\hline & $\mathrm{A}$ & $\mathrm{B}$ & $\mathrm{C}$ & $\mathrm{D}$ & $\mathrm{E}$ & $\mathrm{F}$ & $\mathrm{G}$ & $\mathrm{H}$ \\
\hline PPIEN & 1,000 & & & & & & & \\
INDEP & 0,292 & 1,000 & & & & & & \\
LEIS & 0,408 & 0,159 & 1,000 & & & & & \\
REGQUAL & 0,546 & 0,194 & 0,853 & 1,000 & & & & \\
CCORRUP & 0,475 & 0,212 & 0,922 & 0,854 & 1,000 & & & \\
ESTPOL & 0,347 & 0,076 & 0,701 & 0,636 & 0,656 & 1,000 & & \\
EFICGOV & 0,541 & 0,211 & 0,903 & 0,868 & 0,927 & 0,656 & 1,000 & \\
CINIC & $-0,248$ & $-0,052$ & $-0,444$ & $-0,565$ & $-0,377$ & $-0,271$ & $-0,370$ & 1,000 \\
PERMIT & $-0,051$ & $-0,019$ & $-0,285$ & $-0,452$ & $-0,227$ & $-0,186$ & $-0,180$ & 0,856 \\
CREGPROP & $-0,346$ & $-0,073$ & $-0,361$ & $-0,487$ & $-0,283$ & $-0,290$ & $-0,314$ & 0,486 \\
PROTINV & 0,215 & 0,202 & 0,325 & 0,352 & 0,322 & 0,066 & 0,434 & $-0,112$ \\
PESOIMP & 0,222 & 0,093 & $-0,078$ & $-0,110$ & $-0,010$ & $-0,110$ & 0,009 & $-0,022$ \\
INFMED & $-0,314$ & 0,053 & $-0,248$ & $-0,325$ & $-0,224$ & $-0,139$ & $-0,259$ & 0,389 \\
RENDA & 0,548 & 0,114 & 0,472 & 0,588 & 0,545 & 0,445 & 0,570 & $-0,382$ \\
INDUSTRIA & $-0,010$ & $-0,252$ & $-0,032$ & $-0,111$ & $-0,050$ & 0,006 & $-0,032$ & 0,020 \\
EFENERG & 0,320 & 0,177 & 0,242 & 0,334 & 0,359 & 0,107 & 0,227 & $-0,234$ \\
\hline
\end{tabular}

Legenda: A = PPIEN, B = INDEP, C = LEIS, D = REGQUAL, E = CCORRUP, F = ESTPOL, $\mathrm{G}=$ EFICGOV, $\mathrm{H}=\mathrm{CINIC}$

Tabela 4: Correlação em Pares (continuação)

\begin{tabular}{lrrrrrrrr}
\hline & A & B & C & D & E & F & G & H \\
\hline PERMIT & 1,000 & & & & & & & \\
CREGPROP & 0,398 & 1,000 & & & & & & \\
PROTINV & $-0,069$ & $-0,082$ & 1,000 & & & & & \\
PESOIMP & $-0,012$ & $-0,070$ & $-0,141$ & 1,000 & & & & \\
INFMED & 0,287 & $-0,019$ & 0,038 & 0,004 & 1,000 & & & \\
RENDA & $-0,260$ & $-0,458$ & 0,127 & 0,221 & $-0,112$ & 1,000 & & \\
INDUSTRIA & $-0,086$ & $-0,019$ & 0,089 & 0,100 & 0,168 & 0,372 & 1,000 & \\
EFENERG & $-0,269$ & $-0,134$ & $-0,096$ & 0,220 & $-0,279$ & 0,494 & 0,024 & 1,000 \\
\hline
\end{tabular}

Legenda: $\mathrm{A}=$ PERMIT, $\mathrm{B}=$ CREGPROP, $\mathrm{C}=$ PROTINV, $\mathrm{D}=$ PESOIMP, $\mathrm{E}=$

INFMED, $\mathrm{F}=$ RENDA, $\mathrm{G}=$ INDUST, $\mathrm{H}=$ EFENERG

à governança institucional e ao ambiente para negócios, o presente trabalho identifica dez indicadores que podem ser utilizados e que enfocam diferentes facetas desses aspectos. Conforme apresentado na Tabela 4, as variáveis relacionadas à governança institucional e ao ambiente de negócios são, em sua maior parte, correlacionadas entre si; logo, a inclusão simultânea dessas variáveis dificultaria a análise dos resultados econométricos em virtude da possibilidade de existência de multicolinearidade. Além disso, a inclusão de muitas variáveis simultaneamente reduz os graus de liberdade dos testes de forma significativa, dado o limitado tamanho da amostra.

Desta forma, previamente à condução da análise econométrica, foi realizada a análise fatorial com o objetivo de estimar um conjunto reduzido de índices que resumisse as diferentes variáveis em questão. Esta seção tem por objetivo detalhar os procedimentos metodológicos e apresentar os resultados obtidos com a análise econométrica.

\subsection{Análise Fatorial}

O objetivo da análise fatorial é combinar variáveis intercorrelacionadas em poucas variáveis latentes ou índices. Estes índices ou fatores (score factors) podem, então, ser utilizados na análise econométrica. A análise fatorial também 
permite estimar as correlações das variáveis originais com cada fator (factor loadings); ou seja, a contribuição de cada variável original com os fatores estimados.

Existem algumas metodologias distintas para se estimar os fatores e os resultados obtidos podem ser sensíveis à metodologia escolhida. No entanto, quando as variâncias comuns ou comunalidades ${ }^{12}$ são elevadas — que é o caso do presente trabalho - , resultados semelhantes são obtidos com metodologias distintas, tais como método de verossimilhança máxima, mínimos quadrados generalizados ou mínimos quadrados não ponderados (ver, dentre outros, Hair et al. 2006).

A análise fatorial conduzida aqui se utilizou do método de verossimilhança máxima (maximum likelihood estimation ou MLE), com a matriz de correlação sendo obtida com o procedimento de covariâncias ordinárias de Pearson, já que este permite o cálculo do fator a ser utilizado na análise de regressão. A definição do número de fatores, por sua vez, foi feita com base no método da média parcial mínima, mais acurado que outros métodos comuns utilizados (ver Zwick \& Velicer 1986), enquanto que as estimativas iniciais da variância comum foram calculadas com base na correlação múltipla quadrática.

No primeiro estágio da análise fatorial, foram incluídos os cinco indicadores de governança institucional (LEIS, REGQUAL, CCORRUP, ESTPOL e EFICGOV) e quatro indicadores de facilidade para negócios (CINIC, PERMIT, CREGPROP, PROTINV). ${ }^{13}$ Nesta primeira estimativa, observou-se que PROTINV e CREGPROP apresentaram comunalidades de apenas 0,166 e 0,194, respectivamente. De acordo com Hair et al. (2006), variáveis com comunalidades inferiores a 0,50 devem ser excluídas das estimativas e a análise fatorial deve ser reiniciada.

Os resultados da segunda fase da análise fatorial estão apresentados na Tabela 5. Observa-se que, de acordo com o teste de Kaiser-Meyer-Olkin (KMO), o número de observações da amostra é adequado: esta estatística, que varia entre zero e um, deve ser maior do 0,5 para que a amostra seja válida (ver Field 2000). Adicionalmente, a estatística do teste de esfericidade de Bartlett (BTS) rejeitou, com elevado grau de significância, a hipótese nula de que a matriz de correlação entre as variáveis seja uma identidade: a estatística $\chi^{2}$ de Bartlett foi de 34,53, com probabilidade igual a zero. Não obstante, os resultados obtidos indicaram que as estimativas de unicidade eram não positivas (o grau de comunalidade de PERMIT com um dos fatores é 1), o que pode levar a resultados espúrios. ${ }^{14}$

Dado que CINIC e PERMIT têm baixa correlação com PPIEN, optou-se por reduzir o risco de trabalhar com dados inconsistentes e conduziu-se a análise fatorial novamente, apenas com os indicadores de governança. Na análise de regressão descrita na próxima seção, manteve-se apenas CREGPROP como o indicador representativo para a facilidade de negócios, já que esta foi a única variável de facilidade de negócios que apresentou correlação mais relevante com PPIEN.

\footnotetext{
${ }^{12}$ Variância comum diz respeito à proporção da variância de uma variável que é explicada pelos componentes extraídos.

${ }^{13}$ Variáveis estatisticamente independentes não têm potencial para contribuir na construção de um fator comum e devem ser excluídas da análise. De acordo com Hair et al. (2006), variáveis com correlações inferiores a 0,30 encaixam-se neste perfil. Este é o caso da variável PESOIMP (ver Tabela 4).

${ }^{14}$ Essa ocorrência é chamada de Solução de Heywood.
} 
Tabela 5: Análise Fatorial: Indicadores de Governança e de Ambiente para Negócios

\begin{tabular}{lcccc}
\hline & Extração Fator 1 & Extração Fator 2 & Comunalidade & Unicidade \\
\hline LEIS & 0,908 & $-0,267$ & 0,896 & 0,104 \\
REGQUAL & 0,783 & $-0,406$ & 0,777 & 0,223 \\
CCORRUP & 0,926 & $-0,211$ & 0,901 & 0,099 \\
ESTPOL & 0,702 & $-0,185$ & 0,527 & 0,473 \\
EFICGOV & 0,935 & $-0,169$ & 0,903 & 0,097 \\
CINICIA & $-0,217$ & 0,837 & 0,747 & 0,253 \\
CPERMIT & 0,000 & 1,000 & 1,000 & 0,000 \\
\hline Factor: & Fator 1 & Fator 2 & & \\
\hline${ }^{*}$ Eigenvalue & 4,496 & 1,514 & & \\
${ }^{*}$ Proporção & $64,22 \%$ & $21,62 \%$ & & \\
Cumulativa & & & & \\
\hline KMO & 0,796 & & & \\
BTS & 34,528 & & & \\
BTS/valor $\mathrm{p}$ & 0,000 & & & \\
Amostra & 86 & & & \\
\hline
\end{tabular}

Na última fase da análise fatorial, que incluiu apenas os indicadores de governança institucional, somente um fator foi extraído: com eigenvalue de 4,105 , este fator explica $82,1 \%$ da variância das variáveis originais (os demais fatores apresentaram eigenvalues muito menores que 1). Como apenas um fator foi identificado, eliminou-se a necessidade de rotação dos fatores.

Na Tabela 6, encontram-se os principais resultados obtidos com a última versão da análise fatorial conduzida. O número de observações da amostra manteve-se adequado, com a estatística de KMO igual a 0,863 (todas as variáveis incluídas na análise apresentaram medidas de adequação da amostra acima de 0,80$).{ }^{15} \mathrm{O}$ valor da estatística BTS, por sua vez, rejeitou, com elevado grau de significância, a hipótese nula de que a matriz de correlação entre as variáveis seja uma identidade. A matriz não rotacionada mostra que as comunalidades são elevadas, logo o fator representa, de forma satisfatória, as variáveis originais.

\subsection{Análise Econométrica}

As equações foram estimadas da seguinte forma:

$$
\begin{aligned}
\text { PPIEN }= & \alpha+\beta_{1} \text { INDEP }+\beta_{2} \text { INST }+\beta_{3} \text { CREGPROP }+ \\
& \beta_{4} \text { INFMED }+\beta_{5} \mathrm{X}+\varepsilon
\end{aligned}
$$

onde INST representa o indicador de governança institucional derivado pela análise fatorial e a matriz X representa as demais variáveis de controle (RENDA, INDUSTRIA e EFENERG).

$\mathrm{O}$ indicador de independência das entidades reguladoras, conforme argumentado acima, pode ser considerada uma variável exógena, dado que se constatou, durante o levantamento de dados, a influência externa de instituições

\footnotetext{
${ }^{15} \mathrm{KMO}$ varia entre zero e um, sendo que o valor obtido deve ser superior a 0,5 para que o tamanho da amostra seja adequado.
} 
Tabela 6: Análise Fatorial: Indicadores de Governança

\begin{tabular}{lccc}
\hline & Extração Fator & Comunalidade & Unicidade \\
\hline LEIS & 0,95 & 0,903 & 0,097 \\
REGQUAL & 0,837 & 0,701 & 0,299 \\
CCORRUP & 0,941 & 0,885 & 0,115 \\
ESTPOL & 0,738 & 0,545 & 0,455 \\
EFICGOV & 0,945 & 0,893 & 0,107 \\
\hline Factor: & & & \\
${ }^{*}$ Eigenvalue & 4 & & \\
${ }^{*}$ Proporção Cumulativa & $82,11 \%$ & \\
\hline KMO & 0,863 & & \\
BTS & 24 & & \\
BTS/valor p & 0,0002 & & \\
Amostra & 88 & & \\
\hline
\end{tabular}

multilaterais na concepção de agências em vários países em desenvolvimento. Além disso, observa-se a ausência de correlação de INDEP com as variáveis institucionais, outro indicativo da exogeneidade de INDEP.

Já no que diz respeito à governança institucional, pode ser considerada uma variável endógena. É possível, por exemplo, que o desenvolvimento institucional e o envolvimento do setor privado no setor de energia sejam resultado de uma terceira variável, como padrões históricos, fatores políticos ou da distribuição desigual de influência de grupos econômicos (ver Kaufmann et al. 2010). Neste caso, é necessário identificar uma variável instrumental que seja correlacionada com a governança institucional, mas que não seja correlacionada com PPIEN. Alguns autores defendem que a governança institucional é normalmente relacionada com a origem legal de cada país, estabelecida através da colonização ou por cópia direta ou mais subjetiva (ver, Acemoglu et al. 2003). Djankov et al. (2002) e Beck et al. (2002) defendem ainda que as tradições legais diferem na prioridade dada à propriedade privada e aos direitos do Estado e na sua capacidade de se adaptar eficientemente a mudanças, impactando, assim, na eficiência com que contratos pactuados são respeitados.

Desta forma, o modelo foi testado inicialmente utilizando o método dos mínimos quadrados ordinários (OLS) e, posteriormente, verificou-se se os resultados eram mantidos quando se pressupunha a endogeneidade do indicador de governança institucional. A análise com variáveis instrumentais foi conduzida empregando-se o método de mínimos quadrados em dois estágios (TSLS). ${ }^{16}$ Foram utilizadas variáveis dummies representando a origem legal como instrumentos para governança institucional: a origem legal de cada país foi classificada como francesa, inglesa, germânica ou socialista, de acordo com informações obtidas em CIA (2007).

No que se refere às demais variáveis de controle, foram consideradas exógenas nos testes econométricos, embora seja plausível argumentar que são

\footnotetext{
${ }^{16} \mathrm{O}$ teste de White nas estimativas com OLS indicou a ausência de heterocedasticidade, conforme reportado na Tabela 7 (a estatística de White testa para a hipótese nula de homocedasticidade). Optou-se, então, por adotar TSLS na análise com variáveis instrumentais. A alternativa seria a adoção do método generalizado dos momentos (GMM), mas este somente produz resultados mais eficientes que TSLS na presença de heterocedasticidade e assintoticamente.
} 
endógenas. É possível, por exemplo, que o crescimento econômico leve a um maior nível de investimento em projetos de infraestrutura com participação de setor privado e, ao mesmo tempo, contribua para o aumento na renda per capita, maior industrialização, maior intensidade energética e maior estabilidade macroeconômica. A estratégia de assumir a exogeneidade dessas variáveis de controle faz com que os seus coeficientes apresentem valores acima do correto e os coeficientes das variáveis exógenas sejam menores do que deveriam. Ou seja, tratar essas variáveis de controle como exógenas é uma estratégia "conservadora", no sentido de que reduz a probabilidade de se encontrar um papel relevante para as variáveis que são de fato exógenas, como INDEP (ver Acemoglu et al. 2003).

\subsection{Independência das Agências Reguladoras e o Investimento Privado em Energia}

De uma forma geral, constatou-se a importância da independência das agências reguladoras e a representatividade do nível de renda e da estabilidade macroeconômica para o fluxo de recursos para projetos de infraestrutura no setor de energia de países em desenvolvimento. Interessante salientar também que, ao contrário de resultados de outros trabalhos empíricos, os indicadores de desenvolvimento institucional não mantiveram significância estatística. Mesmo desempenho foi apresentado pelo indicador de facilidade para realização de negócios e as demais variáveis de controle, que não se mostraram estatisticamente relevantes.

A Tabela 7 apresenta os resultados dos testes econométricos. O indicador de independência da agência reguladora é estatisticamente relevante para o investimento em projetos no setor de energia com participação do setor privado, com um nível de $5 \%$, independentemente da metodologia empregada. Destacam-se, também, a estabilidade macroeconômica, com $5 \%$ de significância estatística, e o nível de renda, cuja relevância estatística varia entre $1 \%$ e $10 \%$, dependendo da metodologia empregada.

Em termos de relevância econômica, considere o exemplo do Brasil: o país apresentou um investimento per capita em projetos de infraestrutura do setor de energia de US\$ 708 e o grau de independência da agência reguladora (ANEEL) foi estabelecido em 0,765. Caso o indicador de independência fosse $10 \%$ mais elevado, o investimento per capita em projetos de energia com participação do setor privado seria de US\$ 938, ceteris paribus; ou seja, um aumento de $10 \%$ no INDEP implicaria em uma elevação no nível de investimento privado per capita em energia de 32,5\%. Em relação à estabilidade macroeconômica, apesar de sua relevância estatística, sua importância em termos econômicos é reduzida: se a taxa de inflação no Brasil reduzisse similarmente em $10 \%$, o investimento privado em projetos de energia em termos per capita cresceria apenas 3,5\%. Já uma elevação de $10 \%$ no nível de renda per capita levaria a um incremento de $6,9 \%$ no investimento per capita em projetos no setor.

É interessante ressaltar que, independente da metodologia econométrica utilizada, os indicadores de governança institucional não apresentam relevância estatística, apesar do sinal do seu coeficiente ser o esperado. A ausência de significância estatística se contrapõe à evidência apresentada por outros autores, conforme salientado anteriormente. Particularmente em Tiryaki (2008a), semelhante estimativa é conduzida, mas sem incorporar o indicador de inde- 
Tabela 7: Resultados dos Testes Econométricos

\begin{tabular}{lclc}
\hline \multicolumn{2}{c}{ OLS } & \multicolumn{2}{c}{ TSLS } \\
\hline Variável & Coeficiente & Variável & Coeficiente \\
\hline C & $-1,895$ & C & $-2,575$ \\
& $(-0,876)$ & & $(-0,772)$ \\
INDEP & $1,596^{* *}$ & INDEP & $1,662^{* *}$ \\
& $(2,223)$ & & $(2,184)$ \\
INST & 0,189 & INST & 0,063 \\
& $(0,985)$ & & $(0,126)$ \\
CREGPROP & $-0,016$ & CREGPROP & $-0,018$ \\
& $(-0,521)$ & & $(-0,553)$ \\
INFMED & $-0,022^{* *}$ & INFMED & $-0,024^{* *}$ \\
& $(-2,222)$ & & $(-2,074)$ \\
RENDA & $0,704^{* * *}$ & RENDA & $0,792^{*}$ \\
& $(2,395)$ & & $(1,794)$ \\
INDUSTRIA & 0,003 & INDUSTRIA & 0,001 \\
& $(0,122)$ & & $(0,027)$ \\
EFENERG & 0,004 & EFENERG & 0,002 \\
& $(0,068)$ & & $(0,029)$ \\
\hline$R^{2}$ & 0,458 & $R^{2}$ & 0,454 \\
$R^{2}$ Ajustado & 0,389 & $R^{2}$ Ajustado & 0,384 \\
Num. Obs. & 63 & Num. Obs. & 63 \\
Estatística F & 6,633 & Estatística F & 6,446 \\
Teste de White: & & Estatística J & 5,665 \\
${ }^{*} n R^{2}$ & 46 & & \\
${ }^{*}$ Prob, $\chi^{2}$ (35) & 0,108 & & \\
${ }^{*}$ Valor na Tabela & 49,8 & & \\
\hline
\end{tabular}

Notas: (i) Números em parêntesis representam as estatísticas t;

(ii) *, ${ }^{* *} \mathrm{e}^{* * *}$ indicam níveis de significância de $10 \%, 5 \%$ e $1 \%$,

respectivamente;

(iii) Instrumentos utilizados: dummies para origem legal germânica,

socialista, francesa e inglesa.

pendência de agências reguladoras, e os resultados obtidos indicam significativa relevância estatística dos indicadores de governança. Destaca-se, também, que a amostra do presente artigo é maior do que aquela utilizada em Tiryaki (2008a), o que pode indicar que os resultados são sensíveis à amostra utilizada e que a inclusão de um número maior de países possibilita alcançar resultados mais definitivos.

Os coeficientes das demais variáveis de controle - INDUSTRIA E EFENERG - também não apresentaram significância estatística, embora ambas variáveis se relacionem positivamente com PPIEN, conforme esperado. No que se refere à robustez dos resultados apresentados, nota-se que estes não são sensíveis à metodologia utilizada: tanto os coeficientes, quanto o seu grau de significância estatística não variam de forma relevante se a análise econométrica é conduzida com OLS ou com TSLS. Observa-se, também, que os valores da estatística $\mathrm{F}$ indicam que as variáveis incluídas como independentes são conjuntamente importantes para explicar a participação do setor privado no setor de energia. Por fim, a estatística $J$ obtida na estimativa com TSLS indica que os instrumentos utilizados — origem legal dos países — são válidos. 


\section{Conclusão}

A provisão de serviços de infraestrutura de qualidade é essencial para estimular o investimento e viabilizar o crescimento econômico sustentado de um país. Restrições fiscais e dificuldades em se garantir uma maior eficiência na atuação estatal nos setores de infraestrutura têm estimulado a busca por uma crescente participação de empresas privadas. Não obstante, o engajamento desses investidores de forma mais efetiva requer um ambiente macroeconômico estável e a eliminação de restrições de caráter político e institucional.

Investimentos em setores de infraestrutura possuem longo prazo de maturação e são direcionados para ativos com utilização específica, o que eleva o risco de perda futura no poder de barganha em negociações com o governo. Essa particularidade é relevante, tendo em vista que a presença de significativas economias de escala e escopo implica na necessidade de uma maior intervenção regulatória do governo. Neste contexto, a estabilidade e confiança no arcabouço regulatório reduzem a percepção de risco por parte dos investidores e podem estimular uma maior participação do setor privado em projetos de infraestrutura.

A evidência empírica apresentada no presente artigo indica que a existência de entidades autônomas confere a credibilidade necessária à atração e retenção do investimento privado no setor de energia de países em desenvolvimento, ainda que tal indicador esteja capturando a independência formal (ao invés de independência de fato). Os resultados apresentados, ao contrário de trabalhos anteriores, evidenciam uma menor importância dos indicadores de governança institucional, o que pode refletir a sensibilidade dos resultados à amostra utilizada. Assim, à medida que novos países passem a incorporar a participação do setor privado no setor, será possível proceder a estimativas mais acuradas.

A estabilidade macroeconômica, por sua vez, mostrou-se particularmente relevante para os investimentos no setor, indicando a aversão de investidores privados em direcionar recursos para países com elevadas taxas de inflação, face ao fato de que é comum que governos manipulem as tarifas dos insumos energéticos como forma de conter a inflação. Por fim, os resultados também evidenciaram a relevância do nível de renda para o investimento privado no setor de energia, já que esta variável constitui um indicador da demanda em potencial por infraestrutura.

É essencial, portanto, o delineamento de medidas que fortaleçam o arcabouço institucional de um país e que viabilizem a autonomia das agências reguladoras. Em um contexto de restrições orçamentárias do setor público, o que é comum em países em desenvolvimento, o estímulo à participação de investidores privados pode viabilizar uma melhor eficiência operacional e eliminar gargalos na provisão de infraestrutura no setor de energia.

\section{Agradecimentos}

Gostaria de agradecer a contribuição de Marcelo Ferreira Costa, Fábia Santos Alves e Carlos Oliveira Fernandes Melo pelo excelente trabalho de levantamento de informações para o banco de dados de independência das agências reguladoras e o apoio do Conselho Nacional de Desenvolvimento Científico e Tecnológico (CNPq). 


\section{Referências Bibliográficas}

Acemoglu, D., Johnson, S., Robinson, J. \& Thaicharoen, Y. (2003), 'Institutional causes, macroeconomic symptoms: Volatility, crises and growth', Journal of Monetary Economics 50(1), 49-123.

Banco Mundial (2011a), 'Ppi database', Washington.

URL: Disponivel em: <http://ppi.worldbank.org> Acesso em 12 de abril de 2011

Banco Mundial (2011b), 'Governance indicators database', Washington.

URL: Disponivel em: <http://info.worldbank.org/governance/wgi/index.asp> Acesso em 8 de março de 2011

Banco Mundial (2011c), 'Doing business database', Washington.

URL: Disponivel em: <http://www.doingbusiness.org > Acesso em 8 de março de 2011

Banco Mundial (2011d), 'World development indicators', Washington. URL: Disponivel em: <http://databank.worldbank.org/ddp/home.do?Step= $12 \mathcal{E} i d=4 \mathcal{E} C N O=2>$ Acesso em 8 de março de 2011

Banerjee, S., Oetzel, J. \& Ranganathan, R. (2006), 'Private provision of infrastructure in emerging markets: Do institutions matter?', Development Policy Review 24(2), 175-202.

Beck, T., Demirguç-Kunt, A. \& Levine, R. (2002), 'Law and finance: why does legal origin matter?', World Bank Policy Research Working Paper (2904), 1-43.

Bergara, M., Henisz, W. \& Spiller, P. (1997), 'Political institutions e electric utility investment: a cross-nation analysis', POWER Working Paper Series (52), 1-28.

Calderon, C. \& Serven, L. (2003), The growth cost of latin america's infrastructure gap, in W. Easterly \& L. Serven, eds, 'Adjustment Undermined? Infrastructure, Public Deficits and Growth in Latin America, 1980-2000', Princeton University Press.

CIA (2007), 'The world factbook', Washington.

URL: Disponivel em: https://www.cia.gov/library/publications/download/download-2007/index.html Acesso em 8 de março de 2011

Cubbin, J. \& Stern, J. (2005), 'Regulatory effectiveness and the empirical impact of variations in regulatory governance: Electricity industry capacity and efficiency in developing countries', World Bank Policy Research Working Paper, (3535), 1-45.

Dixit, A. (1996), The Making of Economic Policy: A Transaction-Cost Politics Approach, 1 edn, MIT Press.

Djankov, S., La Porta, R., Lopez-de Silanez, F. \& Shleifer, A. (2002), 'Courts: the lex mundi project', C.E.P.R. Discussion Papers (3344), 1-69.

Estache, A. \& Goicoechea, A. (2005), 'How widespread were private investment and regulatory reform in infrastructure utilities during the 1990s?', World Bank Policy Research Working Paper (3595), 1-24. 
Field, A. (2000), Discovering Statistics using SPSS for Windows, 1 edn, Sage Publications.

Fundo Monetário Internacional (2006), 'World economic outlook database', Washington, DC: Fundo Monetário Internacional.

URL: Disponivel em: http://www.imf.org/external/pubs/ft/weo/2006/01/data/index.htm Acesso em 04 de Outubro de 2006

Gilardi, F. (2006), 'The formal independence of regulators: A comparison of 17 countries and 7 sectors', Swiss Political Science Review 12(4), 139-167.

Gual, J. \& Trillas, F. (2004), 'Telecommunications policies: Determinants and impact', CEPR Discussion Papers (4578), 1-22.

Guasch, J. L. (2004), Granting and Renegotiating Infrastructure Concessions Doing it Right, 1 edn, World Bank.

Gutierrez, L. H. (2003), 'The effect of endogenous regulation on telecommunications expansion and efficiency in latin america', Journal of Regulatory Economics 23(3), 257-286.

Hair, J., Black, W. C., Babin, B. J., Anderson, R. E. \& Tatham, R. L. (2006), Multivariate Data Analysis, 6 edn, Pearson Prentice Hall.

Henisz, W. (2002), 'The institutional environment for infrastructure investment', Industrial and Corporate Change 11(2), 355-389.

Jensen, O. \& Blanc-Brude, F. (2006), 'The handshake: Why do governments and firms sign private sector participation deals? evidence from the water and sanitation sector in developing countries', World Bank Policy Research Working Paper (3937), 1-25.

Kaufmann, D., Kraay, A. \& Mastruzzi, M. (2010), 'The worldwide governance indicators: Methodology and analytical issues', World Bank Policy Research Working Paper (5430), 1-29.

Levy, B. \& Spiller, P. T. (1996), Regulation, Institutions, and Commitment: Comparative Studies of Telecommunications, 1 edn, Cambridge University Press.

Oliveira, G., Machado, E. L., Novaes, L. M. \& Ferreira, C. B. G. (2005), Aspects of the Independence of Regulatory Agencies and Competition Advocacy, 1 edn, Fundação Getúlio Vargas.

Olson, M. (1965), The Logic of Collective Action, 1 edn, Harvard University Press.

Pargal, S. (2003), 'Regulation and private sector investment in infrastructure - evidence from latin america', World Bank Policy Research Working Paper (3037), 1-43.

Peltzman, S. (1976), 'Toward a more general theory of regulation', Journal of Law and Economics 19(2), 211-240.

Reinikka, R. \& Svensson, J. (1999), 'How inadequate provision of public infrastructure and services affect private investment', World Bank Policy Research Working Paper (2262), 1-26. 
Stigler, G. J. (1971), 'The theory of economic regulation', Bell Journal of Economics and Management Science 2(1), 3-21.

Tiryaki, G. F. (2008a), 'Aspectos de governança, ambiente para negócios e o investimento privado no setor de energia de países em desenvolvimento.', Revista Brasileira de Energia 14(2), 27-45.

Tiryaki, G. F. (2008b), 'Desenvolvimento institucional e o envolvimento do setor privado na provisão de infraestrutura', Economia Aplicada 12(3), 499525.

Viscusi, K., Harrington, J. E. \& Vernon, J. M. (2005), Economics of Regulation and Antitrust, 4 edn, MIT Press.

Wallsten, S. J. (2002), 'Does sequencing matter? regulation and privatization in telecommunications reforms', World Bank Policy Research Working Paper (2817), 1-21.

Zwick, W. R. \& Velicer, W. F. (1986), 'Comparison of five rules for determining the number of components to retain', Psychological Bulletin 99(3), 432442. 


\section{Apêndice A}

Tabela A.1: Legislação de constituição de agências reguladoras

\begin{tabular}{|c|c|c|c|}
\hline País & Legislação & Setor & Site \\
\hline África do Sul & Act $N^{\circ} .40$, de $30 / 3 / 2005$ & Energia & www. nersa.org.za \\
\hline Albânia & $\begin{array}{l}\text { Lei No. } 9072 \text {, de } 22 / 5 / 2003 \text { e Lei } \\
N^{o} .9946 \text {, de } 30 / 6 / 2008\end{array}$ & Energia & www.ere.gov.al \\
\hline Algéria & Lei $N^{\circ}$. 02-01 de 5/2/2002 & Energia & www. creg.gov.dz \\
\hline Angola & $\begin{array}{l}\text { Estatuto do Instituto Regulador } \\
\text { do Sector Eléctrico (IRSE) }\end{array}$ & Eletricidade & www.irse.co.ao \\
\hline Argentina & $\begin{array}{l}\text { Lei } N^{\circ} \text {. 24065, 6/8/1992; e Lei } \\
N^{\circ} .24076 \text {, de 9/6/1992 }\end{array}$ & Energia & $\begin{array}{l}\text { www. enre.gov. ar e wWw. } \\
\text { enargas.gov.ar }\end{array}$ \\
\hline Armênia & Lei da PSRC, de 25/12/2004 & $\begin{array}{l}\text { Serviços } \\
\text { Públicos }\end{array}$ & wWw.psrc.am \\
\hline Azerbaijão & Decreto $N^{\circ} .341$, de 26/12/2005 & $\begin{array}{l}\text { Serviços } \\
\text { Públicos }\end{array}$ & $\begin{array}{l}\text { www. tariffcouncil. } \\
\text { gov.az }\end{array}$ \\
\hline Bangladesh & Act $N^{o} .13$, de $24 / 7 / 2003$ & Energia & wWw. berc.org.bd \\
\hline Belize & $\begin{array}{l}\text { Public Utilities Commission Act, } \\
\text { Chapter } 223 \text {, de } 31 / 12 / 2000\end{array}$ & $\begin{array}{l}\text { Serviços } \\
\text { Públicos }\end{array}$ & www.puc.bz \\
\hline Bolívia & Lei 1600 , de $28 / 10 / 1994$ & $\begin{array}{l}\text { Serviços } \\
\text { Públicos }\end{array}$ & $\begin{array}{l}\text { WWW. superele.gov.boe } \\
\text { wWW. superhid.gov.bo }\end{array}$ \\
\hline Bósnia & $\begin{array}{l}\text { Law on Transmission of Elec- } \\
\text { tric Power, Regulator and Sys- } \\
\text { tem Operator of Bosnia and Her- } \\
\text { zegovina, } 2002\end{array}$ & Eletricidade & www.ferk.ba \\
\hline Brasil & $\begin{array}{l}\text { Lei No. 9427, } 1996 \text { (versão atu- } \\
\text { alizada com modificações imple- } \\
\text { mentadas em 1997, 1998, 1999, } \\
2002 \text { e 2003) }\end{array}$ & Eletricidade & wWw. aneel.gov.br \\
\hline Bulgária & Lei No. 107 , de 9/12/2003 & Energia & www.dker.bg \\
\hline Burkina Faso & Lei $N^{\circ} .027$, de 20/11/2007 & Eletricidade & N.D. \\
\hline Butão & Electricity Act of Bhutan, 2001 & Eletricidade & wWw.bea.gov.bt \\
\hline Cabo Verde & $\begin{array}{l}\text { Decreto-Lei n. }{ }^{\circ} \quad 26 / 2003 \text { e } \\
\text { Decreto-Lei n. }{ }^{\circ} \text { 27/2003 }\end{array}$ & $\begin{array}{l}\text { Serviços } \\
\text { Públicos }\end{array}$ & www. are.cv \\
\hline Camarões & $\begin{array}{l}\text { Lei } N^{\circ} .98 / 022 \text { de } 24 / 12 / 1998 \\
\text { e Decreto } N^{\circ} . \\
15 / 6 / 1999\end{array}$ & Eletricidade & WWW. arsel. cm \\
\hline Camboja & $\begin{array}{l}\text { Decreto Real No. 0201/03 de } \\
2 / 2 / 2001\end{array}$ & Eletricidade & www. eac.gov.kh \\
\hline Cazaquistão & Lei No. 1109 , de $28 / 10 / 2004$ & $\begin{array}{l}\text { Serviços } \\
\text { Públicos }\end{array}$ & www. regulator.kz \\
\hline Chile & $\begin{array}{l}\text { Lei } N^{\circ} . \quad 18410 \text { de } 22 / 5 / 1985 \\
\text { modificada pela Lei } N^{\circ} .19613 \\
\text { de } 08 / 06 / 1999\end{array}$ & Energia & wWw. cne.cl \\
\hline China & 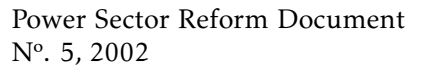 & Eletricidade & WWW.serc.gov.cn \\
\hline
\end{tabular}


Tabela A.1: Legislação de constituição de agências reguladoras (continuação)

\begin{tabular}{|c|c|c|c|}
\hline País & Legislação & Setor & Site \\
\hline Colômbia & $\begin{array}{l}\text { Leis } \mathrm{N}^{\circ} .142 \text { e } \mathrm{N}^{\circ} .143 \text {, de } \\
12 / 7 / 1994\end{array}$ & Energia & www.creg.gov.co \\
\hline $\begin{array}{l}\text { Costa do Mar- } \\
\text { fim }\end{array}$ & $\begin{array}{l}\text { Decreto } N^{\circ} . \\
16 / 12 / 1998\end{array}$ & Eletricidade & wWw. anare.ci \\
\hline Costa Rica & 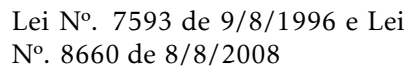 & $\begin{array}{l}\text { Serviços } \\
\text { Públicos }\end{array}$ & www. aresep.go.cr \\
\hline Croácia & $\begin{array}{l}\text { Law on Regulation of Energy Ac- } \\
\text { tivities, } 2001\end{array}$ & Energia & www.hera.hr \\
\hline Cuba & N.D. & N.D. & N.D. \\
\hline Dominica & Act $N^{o} .10$, de $9 / 11 / 2006$ & Energy & wWw.dominica.gov.dm \\
\hline Egito & $\begin{array}{l}\text { Decreto } N^{\circ} .326 \text { de } 12 / 1997 \text { e } \\
\text { Decreto } N^{\circ} .339 \text {, de } 21 / 8 / 2000\end{array}$ & Eletricidade & www.egyptera.com \\
\hline El Salvador & Decreto $N^{\circ} .808$, de 12/9/1996 & Eletricidade & www.siget.gob.sv \\
\hline Equador & $\begin{array}{l}\text { Ley de Régimen del Sector Eléc- } \\
\text { trico, de } 10 / 10 / 1996\end{array}$ & Eletricidade & WWW.conelec.gob.ec \\
\hline Filipinas & $\begin{array}{l}\text { Republic Act } N^{\circ} \text {. 9136, de } \\
8 / 6 / 2001\end{array}$ & Energia & wWw.erc.gov.ph \\
\hline Gabão & N.D. & N.D. & N.D. \\
\hline Gâmbia & $\begin{array}{l}\text { Gambia Public Utilities Regula- } \\
\text { tory Authority Act, } 2001\end{array}$ & $\begin{array}{l}\text { Serviços } \\
\text { Públicos }\end{array}$ & www.pura.gm \\
\hline Gana & $\begin{array}{l}\text { Acts } N^{\circ} .538 \text { e } N^{\circ} .541 \text {, de } \\
16 / 10 / 1997 \text { e de } 31 / 12 / 1997\end{array}$ & $\begin{array}{l}\text { Serviços } \\
\text { Públicos }\end{array}$ & WWW.purc.com.gh \\
\hline Geórgia & $\begin{array}{l}\text { Georgian Law on Electricity and } \\
\text { Natural Gas, de } 1 / 9 / 2007\end{array}$ & Energia & www.gnerc.org \\
\hline Granada & N.D. & N.D. & N.D. \\
\hline Guatemala & Decreto $93-96$, de 21/11/1996 & Eletricidade & WwW. cnee.gob.gt \\
\hline Guiana & Act $N^{\circ} .31$, de $24 / 10 / 1997$ & Energia & $\begin{array}{l}\text { www. electricity.gov. } \\
\text { gy }\end{array}$ \\
\hline Haiti & N.D. & N.D. & N.D. \\
\hline Honduras & Decreto No. 158 , de 26/11/1994 & Energia & WWW. cne.gob.hn \\
\hline $\begin{array}{l}\text { Ilhas Maurí- } \\
\text { cio }\end{array}$ & $\begin{array}{l}\text { The Utility Regulatory Autority } \\
\text { Bill No. XXXIV, de } 20 / 8 / 2004\end{array}$ & $\begin{array}{l}\text { Serviços } \\
\text { Públicos }\end{array}$ & N.D. \\
\hline Índia & $\begin{array}{l}\text { Commisions Act } N^{\circ} .16 \text { e No. } 36 \text {, } \\
\text { de } 2 / 7 / 1998 \text { e de } 2 / 6 / 2003\end{array}$ & Eletricidade & WWw. cercind.gov. in \\
\hline $\begin{array}{l}\text { Indonésia } \\
\text { Jamaica }\end{array}$ & $\begin{array}{l}\text { N.D. } \\
\text { Acts No. } 13 \text { e } N^{o} . \quad 14 \text {, de } \\
\text { 25/4/1995 e de } 2000\end{array}$ & $\begin{array}{l}\text { N.D. } \\
\text { Serviços } \\
\text { Públicos }\end{array}$ & $\begin{array}{l}\text { N.D. } \\
\text { www. our.org. jm }\end{array}$ \\
\hline Jordão & Lei $\mathrm{N}^{\circ} .64$, de 2002 & Eletricidade & www.erc.gov. jo \\
\hline Laos & N.D. & N.D. & N.D. \\
\hline Lesoto & $\begin{array}{l}\text { Lesotho Electricity Authority } \\
\text { Act, } 2001\end{array}$ & Eletricidade & www. lea.org.ls \\
\hline Letônia & $\begin{array}{l}\text { Law on Regulators of Public Uti- } \\
\text { lities, de } 19 / 10 / 2000\end{array}$ & $\begin{array}{l}\text { Serviços } \\
\text { Públicos }\end{array}$ & www.sprk.gov.lv \\
\hline Lituânia & Lei No. IX-884, 16/5/2002 & $\begin{array}{l}\text { Serviços } \\
\text { Públicos }\end{array}$ & www. regula.lt \\
\hline
\end{tabular}


Tabela A.1: Legislação de constituição de agências reguladoras (continuação)

\begin{tabular}{|c|c|c|c|}
\hline País & Legislação & Setor & Site \\
\hline Macedônia & 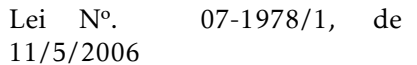 & Energy & www.erc.org.mk \\
\hline Madagascar & $\begin{array}{l}\text { Lei } N^{\circ} .98-032 \text { de } 20 / 1 / 1999 \text { e } \\
\text { Decreto } N^{\circ} .803 \text { de } 4 / 3 / 2003\end{array}$ & Eletricidade & N.D. \\
\hline Malásia & Act No. 610, de 2001 & Energia & www.st.gov.my \\
\hline Mali & $\begin{array}{l}\text { Decreto } N^{\circ} . \\
14 / 4 / 2000\end{array}$ & Eletricidade & N.D. \\
\hline México & $\begin{array}{l}\text { Lei da Comisión Reguladora de } \\
\text { Energía, de } 31 / 10 / 1995\end{array}$ & Energia & www.cre.gob.mx \\
\hline Mianmar & N.D. & N.D. & N.D. \\
\hline Moçambique & Decreto $25 / 2000$, de $3 / 10 / 2000$ & Eletricidade & www.cnelec.org.mz \\
\hline Moldova & 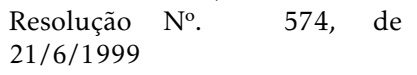 & Energia & www. anre.md \\
\hline Montenegro & Lei de Energia, de 06/2003 & Energia & WwW.regagen.co.me \\
\hline Namíbia & Act $N^{\circ} .04$, de $18 / 10 / 2007$ & Eletricidade & www. ecb.org.na \\
\hline Nepal & $\begin{array}{l}\text { Nepal Electricity Authority Act } \\
\text { No. }^{\circ} 2041 \text {, de } 12 / 11 / 1984\end{array}$ & Eletricidade & www.nea.org.np \\
\hline Nicarágua & $\begin{array}{l}\text { Decreto } N^{\circ} \text {. } 87 \text {, de 23/5/1985; } \\
\text { Lei No. 272, de 23/4/1998; De- } \\
\text { creto } N^{\circ} \text {. 42-98, de 23/06/1998; } \\
\text { e Decreto } N^{\circ} \text {. 128-99, de } \\
16 / 12 / 1999\end{array}$ & Energia & WwW. ine.gob.ni \\
\hline Nigéria & Eletric Power Reform Act, 2005 & Eletricidade & wWW. nercng.org \\
\hline Panamá & $\begin{array}{l}\text { Lei No. } 26 \text {, de } 29 / 1 / 1996 \text { e De- } \\
\text { creto No. } 279 \text {, de } 14 / 11 / 2006\end{array}$ & $\begin{array}{l}\text { Serviços } \\
\text { Públicos }\end{array}$ & WWw . asep.gob.pa \\
\hline $\begin{array}{l}\text { Papua Nova } \\
\text { Guiné }\end{array}$ & Act $\mathrm{N}^{\circ} .06$, de $27 / 2 / 2002$ & $\begin{array}{l}\text { Serviços } \\
\text { Públicos }\end{array}$ & WWW. iccc.gov.pg \\
\hline Paquistão & Act $N^{\circ} .40$, de $16 / 12 / 1997$ & Eletricidade & www. nepra.org.pk \\
\hline Peru & $\begin{array}{l}\text { Lei } N^{\circ} \text {. 26734, de 31/12/1996; } \\
\text { Lei } N^{\circ} \text {. 27332, de 29/7/2000; e } \\
\text { Decreto } N^{\circ} \text {. 054-2001 }\end{array}$ & Energia & WWW.osinerg.gob.pe \\
\hline Polônia & Energy Law, de 10/4/1997 & Energia & www.ure.gov.pl \\
\hline Quênia & Energy Act, 2006 & Energia & www.erc.go.ke \\
\hline $\begin{array}{l}\text { República } \\
\text { Dominicana }\end{array}$ & Lei No. $125-01$, de $26 / 7 / 2001$ & Eletricidade & www.sie.gov.do \\
\hline Romênia & Electricity Law, 8/7/1993 & Eletricidade & www. anre.ro \\
\hline Ruanda & Lei No. 39, de 13/9/2001 & $\begin{array}{l}\text { Serviços } \\
\text { Públicos }\end{array}$ & www.rura.gov.rw \\
\hline Rússia & N.D. & N.D. & N.D. \\
\hline Santa Lúcia & N.D. & N.D. & N.D. \\
\hline Senegal & $\begin{array}{l}\text { Lei } N^{\circ} \text {. } 98-29 \text {, de } 14 / 4 / 1998 \\
\text { e Decreto } N^{\circ} \text {. 98-333, de } \\
21 / 4 / 1998\end{array}$ & Eletricidade & wWw.crse.sn \\
\hline Sri Lanka & Act $\mathrm{N}^{\circ} .35$, de 2002 & $\begin{array}{l}\text { Serviços } \\
\text { Públicos }\end{array}$ & WWW.pucsl.gov.1k \\
\hline
\end{tabular}


Tabela A.1: Legislação de constituição de agências reguladoras (continuação)

\begin{tabular}{|c|c|c|c|}
\hline País & Legislação & Setor & Site \\
\hline Tailândia & $\begin{array}{l}\text { Energy Industry Act, de } \\
10 / 12 / 2007\end{array}$ & Energia & www2.erc.or.th \\
\hline Tanzânia & $\begin{array}{l}\text { The Energy And Water Utilities } \\
\text { Regulatory Authority Act, de } \\
4 / 4 / 2001\end{array}$ & $\begin{array}{l}\text { Serviços } \\
\text { Públicos }\end{array}$ & www. ewura.com \\
\hline Tonga & $\begin{array}{l}\text { Tonga Electric Power Board Act, } \\
\text { de } 1988\end{array}$ & Eletricidade & N.D. \\
\hline Trinidad/Tobag & $\begin{array}{l}\text { Trinidad and Tobago Electricity } \\
\text { Commission Ordinance } N^{\circ} \text {. 42, } \\
1945 \text { (versão 01/2006) }\end{array}$ & Eletricidade & www.ttec.co.tt \\
\hline Turquia & $\begin{array}{l}\text { Regulation on the Organization } \\
\text { of the Energy Market Regula- } \\
\text { tory Authority, de } 2001\end{array}$ & Energia & www.emra.org.tr \\
\hline Ucrânia & $\begin{array}{l}\text { Decreto do Presidente da Ucrâ- } \\
\text { nia No. } 213 \text { de } 14 / 3 / 1995\end{array}$ & Energia & wWw.nerc.gov.ua \\
\hline Uganda & $\begin{array}{l}\text { The Electricity Act, Chapter } 145 \text {, } \\
\text { de } 1 / 11 / 1999\end{array}$ & Eletricidade & www.era.or.ug \\
\hline Uruguai & Lei 17598 , de $13 / 12 / 2002$ & Energia & www. ursea.gub.uy \\
\hline Venezuela & $\begin{array}{l}\text { Lei Orgânica do Serviço Elétrico, } \\
\text { de } 31 / 12 / 2001\end{array}$ & Eletricidade & N.D. \\
\hline Vietnam & $\begin{array}{l}\text { Decisão do Primeiro Ministro } \\
N^{0} .258 \text {, de } 19 / 10 / 2005\end{array}$ & Eletricidade & N.D. \\
\hline Zâmbia & $\begin{array}{l}\text { The Energy Regulation Act, } \\
\text { Chapter } 436 \text { of The Laws Of } \\
\text { Zambia, de } 28 / 4 / 1995\end{array}$ & Energia & www.erb.org.zm \\
\hline Zimbábue & $\begin{array}{l}\text { Chapter 13:19, Electricity Act } \\
4 / 2002 \text { (ammendments } 3 / 2003 \\
\text { e 6/2005) }\end{array}$ & Eletricidade & WWW.zerc.co.zW \\
\hline
\end{tabular}




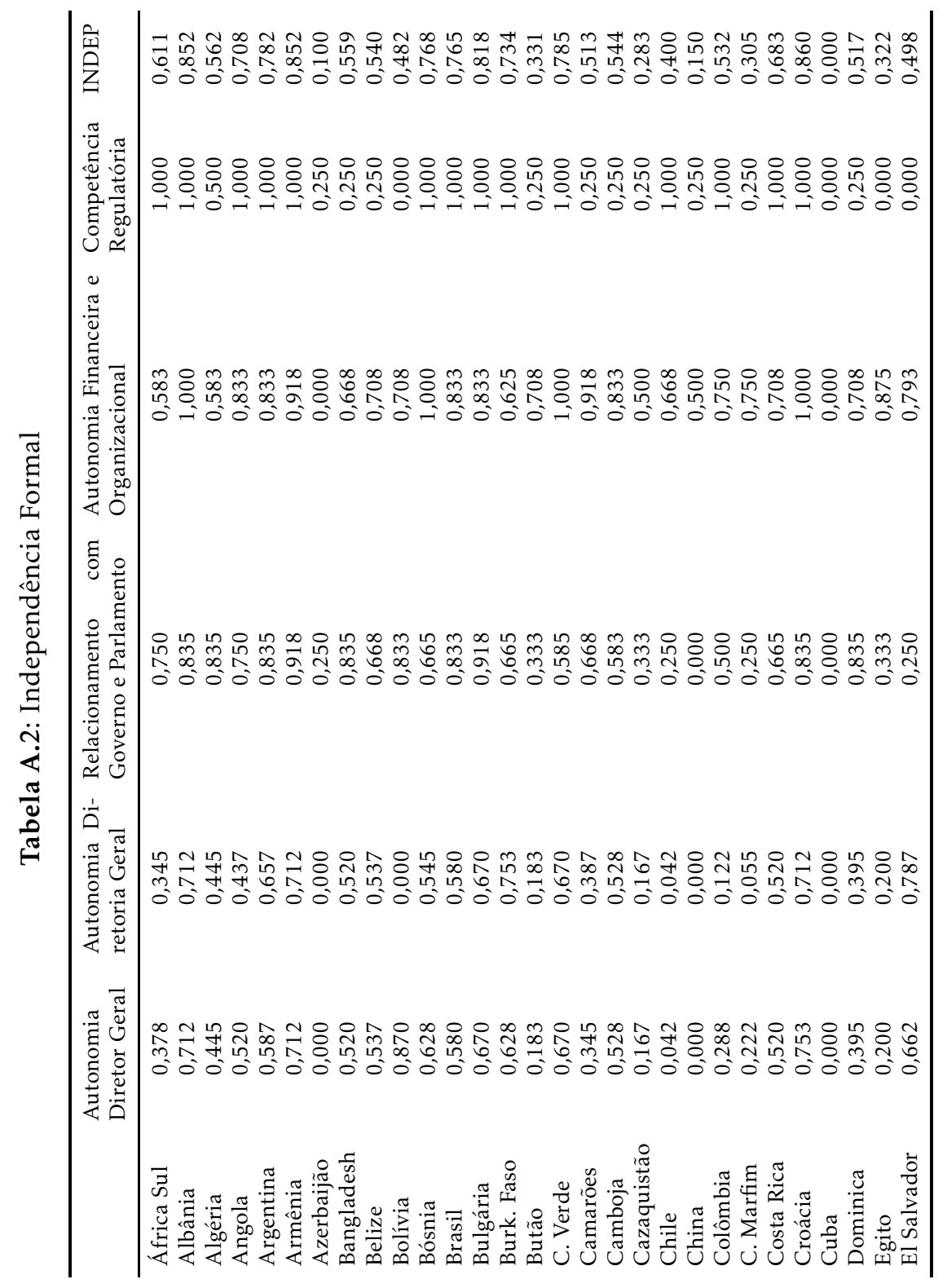




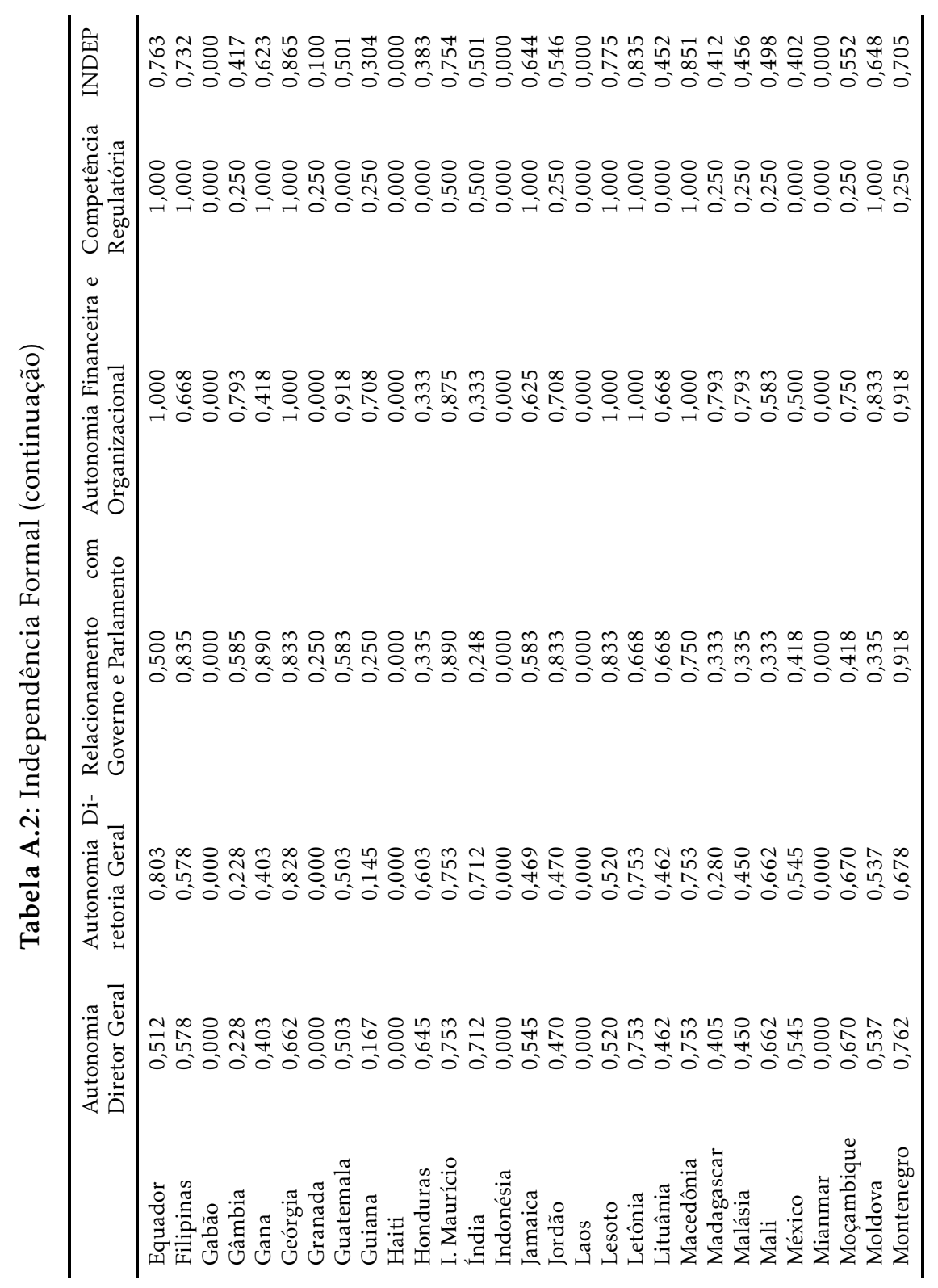




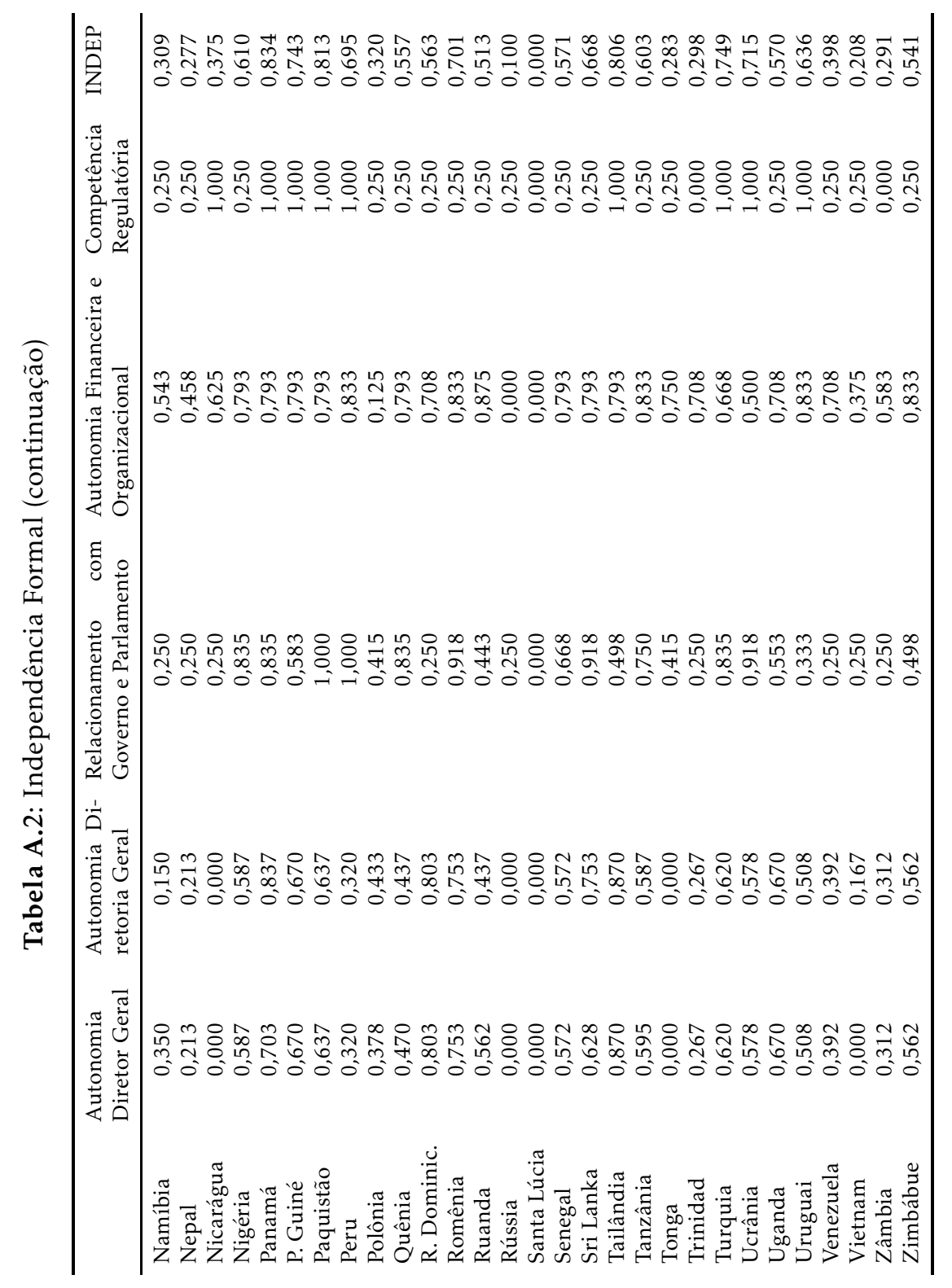

